\title{
Obesity and diet
}

\section{OP36 ADIPOSITY AND CARDIOMETABOLIC RISK MARKERS AMONG INDIAN CHILDREN: COMPARISON WITH INDIAN AND WHITE EUROPEAN CHILDREN IN THE UK}

CM Nightingale, ${ }^{1 *}$ GV Krishnaveni, ${ }^{2}$ AR Rudnicka, ${ }^{1}$ CG Owen, ${ }^{1}$ SR Veena, ${ }^{2}$ JC Hill, ${ }^{3}$ DG Cook, ${ }^{1}$ CHD Fall, ${ }^{3}$ PH Whincup ${ }^{1}$ Division of Population Health Sciences and Education, St George's University of London, London, UK; ${ }^{2}$ Epidemiology Research Unit, CSI Holdsworth Memorial Hospital, Mysore, India; ${ }^{3}$ Medical Research Council Lifecourse Epidemiology Unit, Medical Research Council, Southampton, UK

\subsection{6/jech.2011.143586.36}

Background UK Indian adults have higher risks of coronary heart disease and type 2 diabetes (T2D) than both Indian and UK white European adults. With growing evidence that these risks begin before adulthood, we examined whether differences in adiposity and cardiometabolic risk markers were apparent between Indian children who live in India compared to Indian and white European children who live in the UK.

Methods Comparisons of cardiometabolic markers were based on the Mysore Parthenon Birth Cohort Study, India $(\mathrm{n}=538)$ and the school-based Child Heart Health Study in England (CHASE) ( $\mathrm{n}=483$ UK Indians, 1375 white Europeans) which studied 9-10 year-old children using broadly similar methods in 2007-8 and 2004-7 respectively. Linear regression was used to obtain population differences adjusted for small study differences in age and gender. The effects of adjustment for adiposity, height and pubertal status were also examined.

Findings Compared with Mysore Indians, UK Indians were taller and had markedly higher levels of BMI (\% difference $21 \%$, 95\% CI 18 to $24 \%$ ), combined skinfold thickness (\% difference $34 \%, 95 \%$ CI 26 to $42 \%$ ), Low-density lipoprotein (LDL) cholesterol (mean difference $0.5,95 \%$ CI 0.4 to $0.6 \mathrm{mmol} / \mathrm{l}$ ), systolic blood pressure (BP) (mean difference $12.6,95 \%$ CI 11.0 to $14.1 \mathrm{~mm} \mathrm{Hg}$ ) and fasting insulin (\% difference 145\%, 95\% CI 124 to $168 \%$ ). Compared with white Europeans, UK Indians had higher skinfold thickness (\% difference 6.0\%, 95\% CI 1.5 to $10.7 \%$ ), fasting insulin (\% difference 31\%, 95\% CI 22 to $40 \%$ ), triglyceride (\% difference $13 \%, 95 \%$ CI 8 to $18 \%$ ) and LDL-cholesterol (mean difference $0.1 \mathrm{mmol} / 1,95 \%$ CI 0.0 to $0.2 \mathrm{mmol} / \mathrm{l})$. Both the differences between Mysore and UK Indians and those between UK Indians and white Europeans were similar in boys and girls and little affected by adjustment for adiposity, height or pubertal status.

Interpretation UK Indian children have an adverse cardiometabolic risk profile, especially when compared to Indian children in India, even before puberty. These differences are not simply the result of greater adiposity. Prevention of emerging cardiometabolic risk in Indian diaspora populations needs to begin before adult life. 